\title{
Thin layer shearing of a highly plastic clay
}

\author{
K. Balthasar ${ }^{1}$, G. Gudehus ${ }^{1}$, M. Külzer ${ }^{2}$, and A. B. Libreros Bertini ${ }^{3}$ \\ ${ }^{1}$ Institut für Bodenmechanik und Felsmechanik, Universität Karlsruhe, Germany \\ ${ }^{2}$ Bauer Spezialtiefbau GmbH, Schrobenhausen, Germany \\ ${ }^{3}$ Ed. Züblin AG, Stuttgart, Germany
}

Received: 27 October 2006 - Revised: 23 November 2006 - Accepted: 23 November 2006 - Published: 30 November 2006

\begin{abstract}
Shearing tests with a thin layer of clay between filter slabs render possible large and cyclic deformations with drainage. In the pressure range of $100 \mathrm{kPa}$ they serve to validated visco-hypoplastic constitutive relations. This theory is also confirmed by tests with up to $14 \mathrm{MPa}$ and super-imposed anti-plane cycles. After this kind of seismic disturbance the clay stabilizes if the ratio of permanent stresses is undercritical. Otherwise a spontaneous acceleration occurs after a delay. This could help to understand critical phenomena with clay smears in faults.
\end{abstract}

\section{Introduction}

Saturated highly plastic clays, occuring in sediment layers and as fault gauges (clay smears), reveal high compressibility, density-dependent cohesion, low friction and significant viscosity. For geotechnical applications these properties are determined by standard triaxial and shear tests. Conventional strength and stiffness models are used for their evaluation and for the estimation of stability and deformations. Pore pressures are estimated from hydraulic conditions and with empirical parameters, and allowed for by the principle of effective stress. The viscosity is taken into account at best empirically.

Such mechanical models get invalid for higher pressures and for a wider range of strain rates. Geo-scientists prefer rather different constitutive models: elasticity for wave propagation, perfect plasticity for slow tectonics (Mandl, 1988), the law for viscous flow by Norton (1929), Coulomb friction for dislocating faults. Sophisticated models have been proposed for joints and faults (Shkoller and Minster, 1997), but the internal variables therein could not be identified. There are as yet no comprehensive, objective and physically justi- fied constitutive models for clays which are apt for tectonic applications.

The visco-hypoplastic relations by Niemunis (2003) have been successfully applied for a wide range of geotechnical cases. They are introduced in Sect. 2 for simple shearing by means of diagrams, and by only three equations for friction, compression and viscosity. Further properties are presented graphically by argotropic (i.e. rate-dependent) state limits and limit cycles. Novel thin layer shear tests are described in Sect. 3 which are easier and better apt for validation and identification than usual tests. This is demonstrated by back-analyses with visco-hypoplastic relations.

The thin layer shear tests were also carried out with larger samples and pressures up to $14 \mathrm{MPa}$. For monotonous shearing with different velocities the agreement of observed and calculated resistances (Sect. 4) demonstrates that the viscohypoplastic relation works also for higher pressures. A further validation is obtained for ratcheting, i.e. shearing plus lateral oscillation (Sect. 5). With a higher than critical shear force the latter trigger a dramatic acceleration. The reqired dilation without diffusion of pore water gets possible with cavitation or shear thinning, but both cannot yet be captured by mechanical models.

This is the base for novel applications and further investigations (Sect. 6). The reach of predictions with viscohypoplasticity for geotechnical and seismic engineering is widened. The pressure range can be extended beyond the present maximum value of $14 \mathrm{MPa}$. With additional relations for cavitation and shear thinning the evolution of faults, the cold volcanism and the autogenous ratcheting of faults could be better explained. Combined with further observations this will deepen the understanding of critical phenomena in the lithosphere.

Correspondence to: G. Gudehus

(gerd.gudehus@ibf.uni-karlsruhe.de)

Published by Copernicus GmbH on behalf of the European Geosciences Union and the American Geophysical Union. 

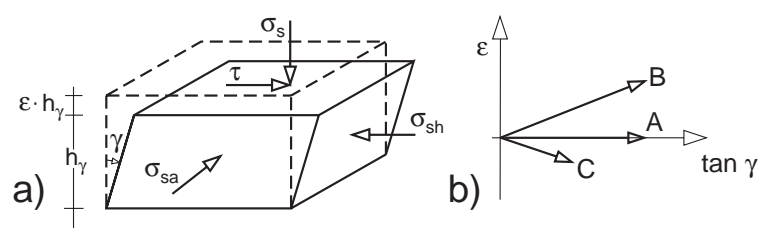

c)

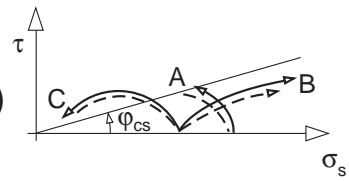

d)

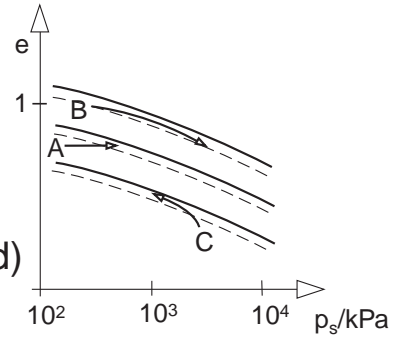

Fig. 1. Representative soil element (RSE) (a), strain paths (b), stress paths (c) and void ratio vs. pressure (d) for moderate and low (dashed) strain rate.

\section{A shortcut of visco-hypoplasticity}

Consider evolutions of a representative soild element (RSE) with monotonous shearing, Fig. 1. The state of the uniform RSE is described by the void ratio $e$, the skeleton normal stress $\sigma_{s}$ and the shear stress $\tau$ (a). The lateral skeleton stresses $\sigma_{s h}$ and $\sigma_{s a}$ in the direction of shearing and orthogonal to it are left aside for simplicity, but the mean pressure $p_{s}=\left(\sigma_{s 1}+\sigma_{s 2}+\sigma_{s 3}\right) / 3$ will be used. Deformations are described by the shearing angle $\gamma$ or $\tan \gamma$ for big amounts, and by the shortening $\varepsilon$ which is negative for dilation. The stretching rates are $\dot{\gamma} \approx d(\tan \gamma) / d t$ and $\dot{\varepsilon}=d \dot{\varepsilon} / d t$, their amount is $D=\sqrt{\dot{\varepsilon}^{2}+2 \dot{\gamma}^{2}}$. The solid particles are assumed to be isochoric, this means $\dot{e}=\dot{\varepsilon}(1+e)$.

Strain paths (Fig. 1b) are imposed with constant dilation ratios: isochoric $(\dot{\varepsilon}=0, \mathrm{~A})$ contractant $(\dot{\varepsilon} /|\dot{\gamma}|>0, \mathrm{~B})$ or dilatant $(\dot{\varepsilon} /|\dot{\gamma}|<0, \mathrm{C})$. The stretching rate $D$, normalized by a material reference rate $D_{r}$, is low or high. The stress path (c) tends to a point with a critical obliquity (A),

$|\tau| / \sigma_{s}=\tan \varphi_{c s}$,

a straight line with increasing $\sigma_{s}$ and lower than critical obliquity (B), or a straight line with decreasing $\sigma_{s}$ and overcritical obliquity (C). The critical friction angle $\varphi_{c s}$ for shearing is close to the one for cylindrical shortening, named $\varphi_{c}$, in case of highly plasic clays. In a plot of $e$ vs. $\log p_{s}$ (d) the state paths tend to nearly straight and parallel lines, i.e.

$e \approx e_{r}-\lambda \ln \left(p_{s} / p_{r}\right)$

with positions depending on obliquity and strain rate. Without volume change (A) a $D$-dependent point is attained. The argotropy can be captured by means of a reference pressure

$p_{r}=p_{r r}\left(D / D_{r}\right)^{I_{v}}$
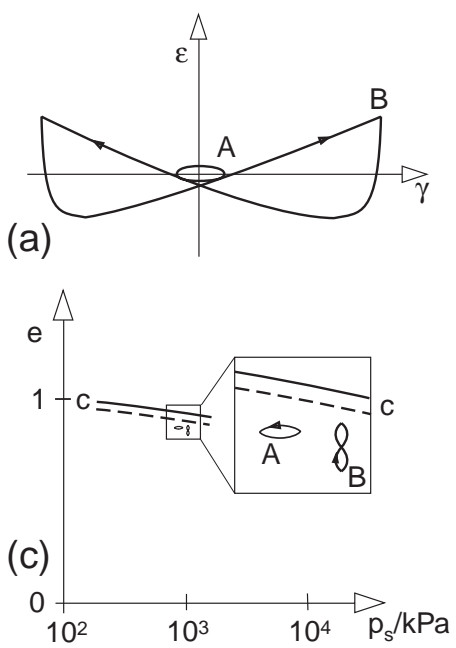

(b)

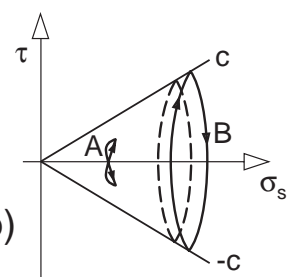

(d)

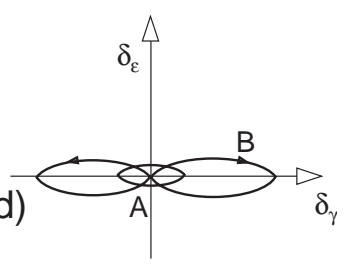

Fig. 2. Strain paths of an RSE for cyclic shearing (a), limit cycles of stress (b), void ratio vs. pressure (c) and intergranular strain (d).

with a constant $p_{r r}$ and a viscosity index $I_{v}$ ranging from ca. 0.02 to 0.05 for lowly to highly plastic clays. For contraction (B) the rate-dependence is again captured by Eq. (2), the slope $-d e / d \ln \left(p_{s} / p_{r}\right)$ represents the compressibility, the $e$ vs. $\log \left(p_{s} / p_{r}\right)$ line is below the critical one. With dilation (C) Eq. (2) works again, and the asymptotic state path is below the critical line. Coulomb's friction law and the viscosity law by Norton (1929) are implied by Eqs. (1) and (3) for critical states.

The visco-hypoplastic relation by Niemunis (2003) produces realistic evolutions in a wider range than in Fig. 1. This was shown by back-analyses of triaxial tests with axial shortening or lengthening for $p_{s}$ from ca. $10^{1}$ to $10^{3} \mathrm{kPa}$ and $D$ from ca. $10^{-8}$ to $10^{-4} \mathrm{~s}^{-1}$. The objective constitutive relation works for arbitrary deformations and was also validated by means of cuboidal and shearing tests. The few parameters can be easily determined from tests with remoulded samples. There are a lot of successful geotechnical applications (Gudehus and Karcher, 2006). The argotropy by Eq. (1) can be explained with thermally activated dislocations (Gudehus, 2004). $I_{v}$ and $D_{r}$ are proportional to the absolute temperature $T$, and the dislocation energy ranges from ca. 0.5 to $1.5 \mathrm{eV}$ for soft to hard clay particles. Following Persson (2000) therein dislocations of nano-sized mono-crystalline blocks are assumed at the contacts of solid particles.

For evolutions with reversals an additional internal state variable named intergranular strain (Niemunis and Herle, 1997 ) is needed. This is shown in Fig. 2 for cyclic shearing with nearly constant $e$ and small amplitude (A), and with nearly constant $\sigma_{s}$ and moderate amplitude (B). The strain path (a) is a small thin lense (A) or tends to a butterflylike double loop (B). The skeleton stress path (b) tends to a minute butterfly (A) or to a bigger lense. In the $e$ vs. $\log p_{s}$ 


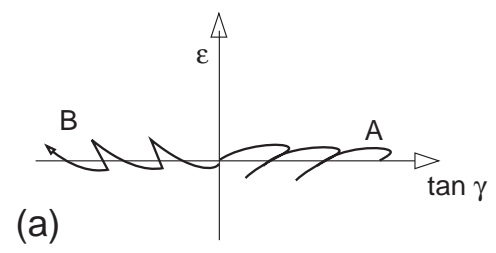

(b)
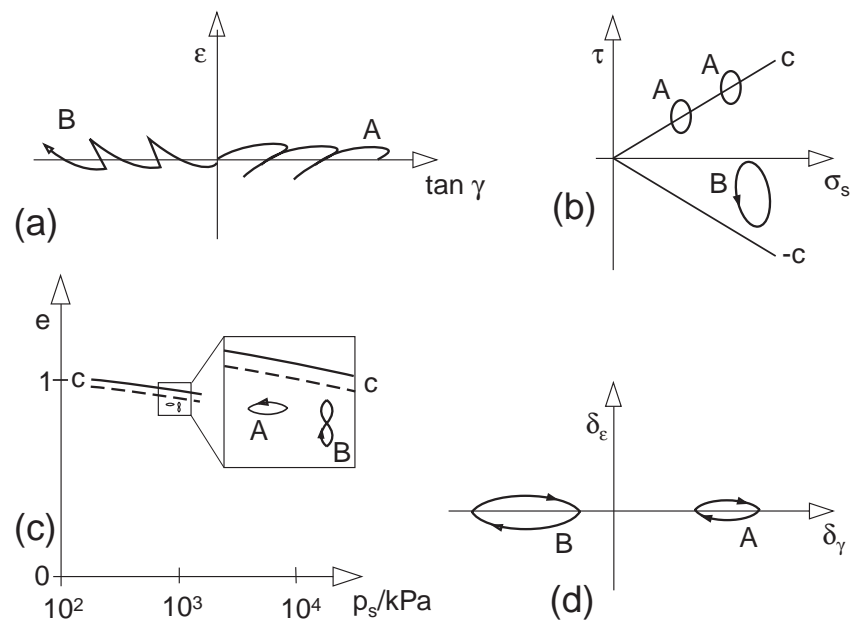

Fig. 3. Strain paths of an RSE for ratcheting (a), (b), (c) and (d) as in Fig. 2.

plot (c) the state path tends to a lenticular (A) or butterflylike (B) limit cycle below the critical line with the same argotropy as in Fig. 1d. In the plane of two intergranular strain components (d) the state path tends to a lenticular small (A) or a bigger butterfly-like (B) limit cycle without argotropy. Small values represent nearly hypoelastic behavior, with bigger deformation the response gets hypoplastic with maximal amount of intergranular strain.

The general visco-hypoplastic relation with intergranular strain by Niemunis (2003) implies an objective interpolation between hypoelastic and visco-hypoplastic ones. It is confirmed for small shear cycles by the $p_{s^{-}}$and $e$-dependence and hysteretic damping observed in resonant column tests $\left(\right.$ Cudmani, 2006 ${ }^{1}$ ). Thus the additional parameters needed for the intergranular strain can be determined. Further validation can be achieved by back-analysis of triaxial and shear tests with repeated reversals and moderate or big amplitude. There are several geotechnical applications with reversals, observations in model tests and in situ provide validations.

The constitutive relation works also for ratcheting, Fig. 3. In the strain plot (a) this means the superposition of isochoric monotonous and of cyclic shearing, the latter resemble cases $A$ or $B$ of Fig. 1a. The stress path (b) tends to an asymmetric lenticular limit cycle with nearly (A) or at most critical obliquity (B). In the $e$ vs. $\log p_{s}$ plot (c) the state path tends to an argotropic lenticular limit cycle with (A) or just (B) below the critical line. In the intergranular strain plot (d) the path tends to an asymmetric limit cycle close to one of the bounds for critical states. Therein $\delta_{\epsilon}$ and $\delta_{\gamma}$ denote normal and tangential components of a tensor of intergranular strain which represents intensity and orientation of spatial fluctuations of stress due to force chains in the skeleton of solid particles.

\footnotetext{
${ }^{1}$ Cudmani, R.: Professorial dissertation, Universität Karlsruhe, Germany, in preparation, 2006.
}

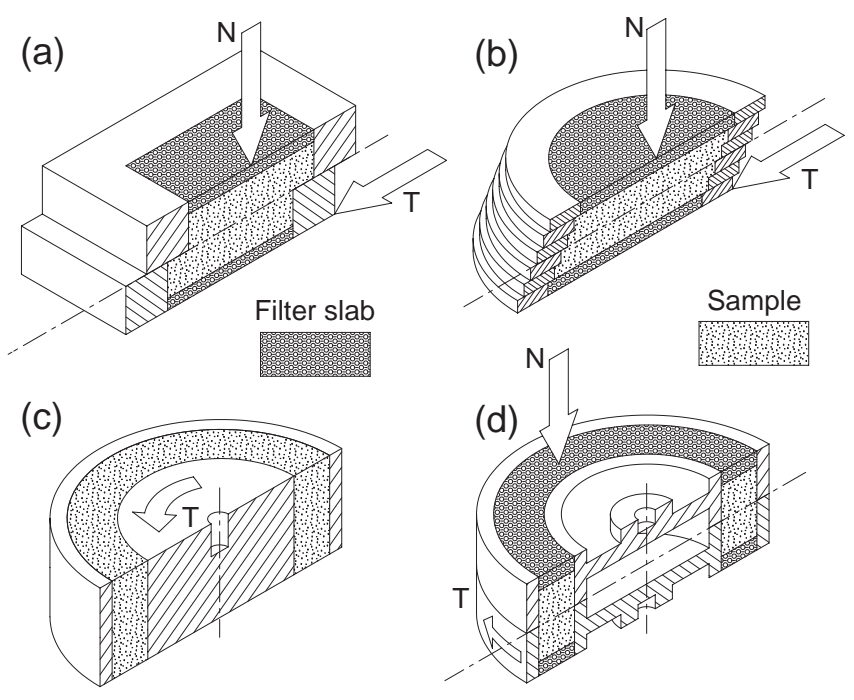

Fig. 4. Simplified cross sections of shearing devices: Dislocated frames (a), stack of rings (b), torsion of hollow against full cylinder (c) and torsion of upper against lower ring (d).

Ratcheting can also be attained by asymmetric shear stress cycles and with other kinds of deformations. It is a more precise substitute of the "cyclic mobility" during earthquakes by Casagrande (1971). In agreement with observations it is more intensive with higher $e$ and with harder solid particles. Apart from one triaxial test by Sangrey et al. (1969) it was not attained in experiments with clay, so there is a lack of data for validation.

\section{Shearing with low pressure}

The usual geotechnical pressure range from ca. $10^{1}$ to $10^{3} \mathrm{kPa}$ is low from the aspect of tectonics. Some usual devices for shearing of clay samples are indicated in Fig. 4. In a direct shear box (a) an average $\bar{\sigma}_{s}$ is imposed by a normal force $N$ via filter slabs and the sample is sheared through by mutual dislocation of frames. In devices with a stack of confining rings (b) the sheared sample remains more uniform, but not with more than ca. $1 \%$ shearing. The Couette aparatus (c) is only apt for clay pastes. Ring shear devices (d) produce a localization which can hardly be controlled. It is rather impossible to follow up the non-uniform evolution in these devices by means of finite elements so that a constitutive relation can be validated.

More uniform deformations can be achieved by cyclic torsion of thick-walled hollow cylindrical sample with control of axial and radial stress components, but such tests are expensive. Shearing of a thin layer with a free rim between filter plates is far simpler and still expedient (Fig. 5). The sample is so thin that the time needed for the diffusion of pore water is lower than the time for shearing. At the free 


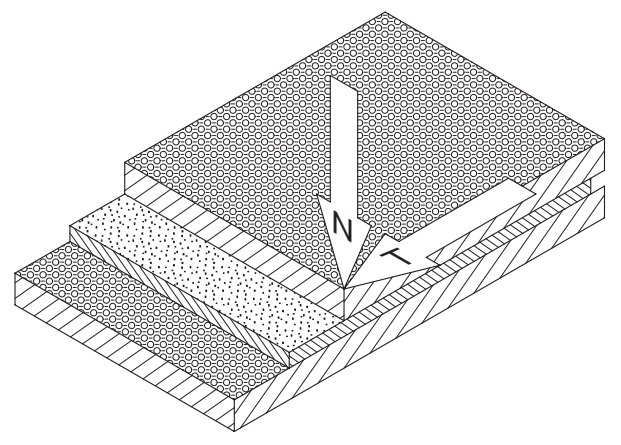

Fig. 5. Simplified cross-section of a device for shearing a thin layer: Sample between two filter slabs.

rim the pore pressure (suction) is determined by the relative humidity of the adjacent air. The average normal pressure $\bar{\sigma}_{s}$ is controlled via the normal force, this can be kept constant in stages. Shearing is imposed via the movable upper filter plate with force or displacement control.

Tests were carried out in a direct shear box (Fig. 4a) with a highly plastic clay. This was placed as a paste (water content $95 \%$, liquid limit $87 \%$ ) in a layer of ca. $6 \mathrm{~mm}$ thickness into the square frame of $60 \mathrm{~mm}$ length and width. Imposing a normal force it was consolidated by increasing the average pressure $\bar{\sigma}_{s}$ up to $1 \mathrm{MPa}$, down to a thickness of approx. $3 \mathrm{~mm}$. Then it was sheared monotonously in the oblong direction with the same $\bar{\sigma}_{s}$ as for the previous consolidation.

In a test with $\bar{\sigma}_{s}=100 \mathrm{kPa}$ and the shearing velocity $\dot{s}=0.4 \mathrm{~mm} / \mathrm{h}$ the average shear stress $\bar{\tau}$ reached a peak and then got almost stationary (Fig. 6a). In another test with $\bar{\sigma}_{s}=180 \mathrm{kPa}$ the shearing velocity alternated between $\dot{s}=0.08$ and $2.2 \mathrm{~mm} / \mathrm{h}$ (b). Every jump of $\dot{s}$ caused a jump of $\tau$, likewise up or down, but after a transition the $\tau$ vs. $s$ curve returned to the one as for a constant $\dot{s}$. The stationary resistance was proportional to $\bar{\sigma}_{s}$, for $\bar{\sigma}_{s}$ from 100 to $180 \mathrm{kPa}$ as by Eq. (1) with $\varphi_{c}=12^{\circ}$. A viscosity index $I_{v}=0.03$ was derived from the $\tau$-jumps after $\dot{s}$-jumps.

A back-analysis with visco-hypoplasticity was carried out by assuming a uniform RSE for spatial average values (Fig. 7). Parameters were adapted to these results and to compression test data. After consolidation, shearing was imposed with the same pressures $\bar{\sigma}_{s}$ and shearing velocities as in the experiments. With $\bar{\sigma}_{s}=100 \mathrm{kPa}$ and $\dot{s}=0.4 \mathrm{~mm} / \mathrm{h}$ the calculated response (a) is almost the same as the observed one shown in Fig. $6 \mathrm{a}$. For $\bar{\sigma}_{s}=180 \mathrm{kPa}$ and $\dot{s}$ alternating from $=0.08$ to $24 \mathrm{~mm} / \mathrm{h}$ (b) the peaks are more marked, and the $\tau$ vs. $s$ curve has a slightly higher asymptote than in Fig. $6 \mathrm{~b}$. Altogether the visco-hypoplastic relation is validated by the agreement of Figs. 6 and 7.

These thin layer tests suffice to determine the friction angle $\varphi_{c s}$ and the viscosity index $I_{v}$. With their size and resolution, however a more detailed analysis would scarcely be worth the effort. At least the stationary stress ratio and the ratio of
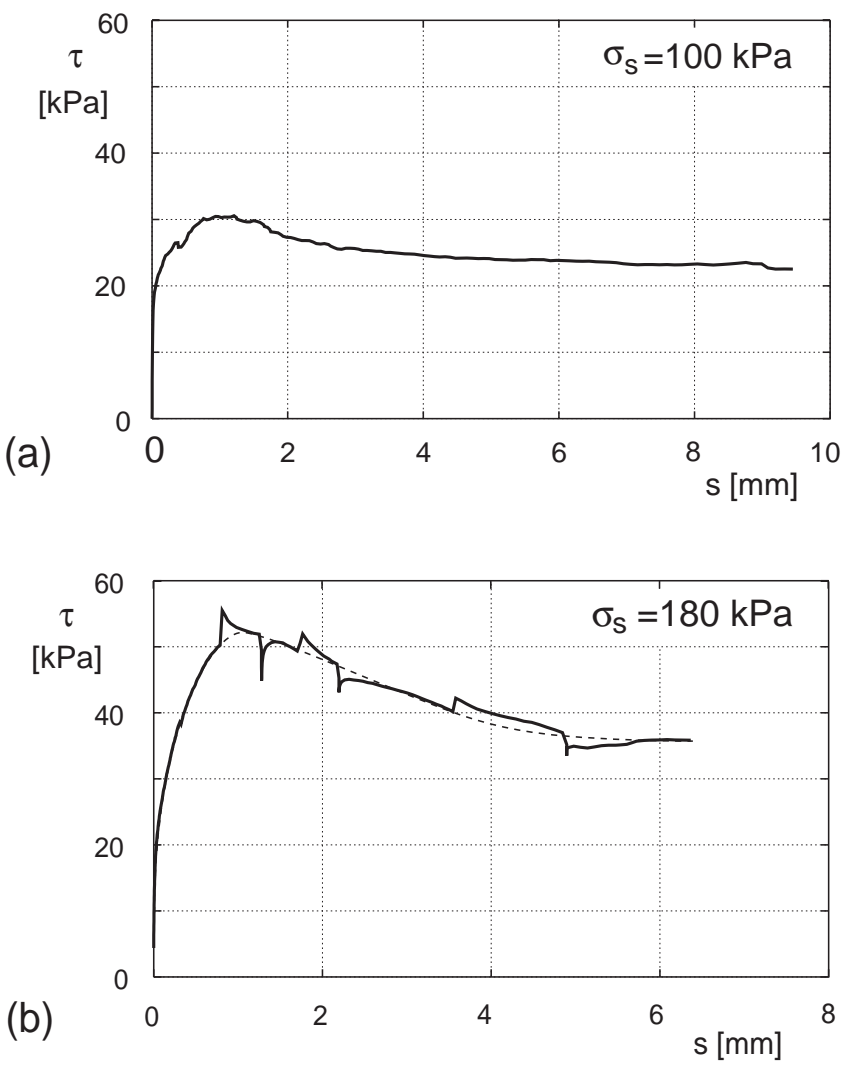

Fig. 6. Results of low pressure thin layer shear tests: shearing resistance with constant shearing velocity (a) and alternating shearing velocity (b).

resistances just after and before a jump of shear rate do not depend on the rather unknown stress distribution.

\section{Shearing with high pressure}

The shearing resistance of rock joints has been investigated in devices as sketched in Fig. 8. Bernaix (1969) used a pair of shear boxes (a), Dieterich (1972) proposed a sandwichlike shearing device (b).

A self-constructed $500 \mathrm{kN}$ shear testing machine for testing rock joints (Fig. 8c) with servo-controlled jacks in a loading frame for force or displacement control in the normal and tangential directions was modified with adapter plates for the shear boxes and filter slabs to take up a thin clay layer according to Fig. 5. A fat clay as in the low-pressure tests was spread as a pancake-like plate of approx. $4 \mathrm{~mm}$ thickness and cut to a layer of $254 \mathrm{~mm}$ length and $126 \mathrm{~mm}$ width. It was placed between the filter slabs (Fig. 9a) and compressed to approx. $3 \mathrm{~mm}$ thickness by different $\bar{\sigma}_{s}$ from 2 to $14 \mathrm{MPa}$ with a load rate of $0.5 \mathrm{MPa} / \mathrm{min}$, then sheared with stepwise constant $\dot{s}$ from $0.002,0.02$ and $0.2 \mathrm{~mm} / \mathrm{min}$ up to approx. $5 \mathrm{~mm}$. After the test the hard layer revealed a wavy 
(a)

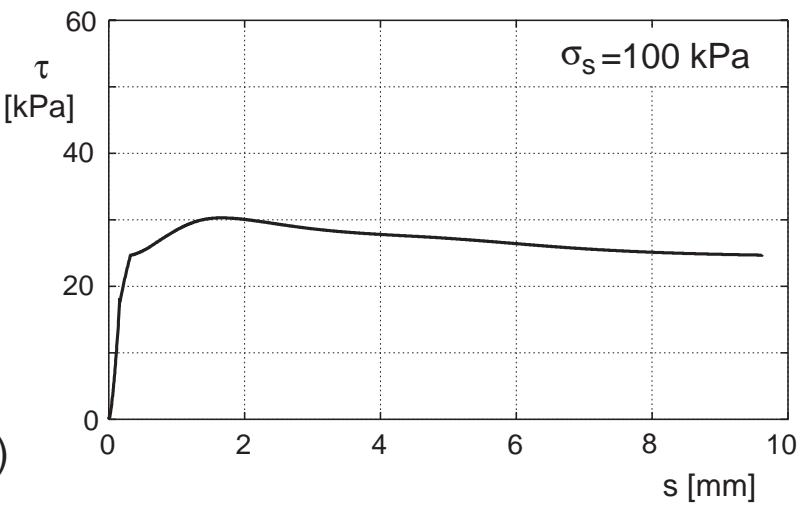

(b)

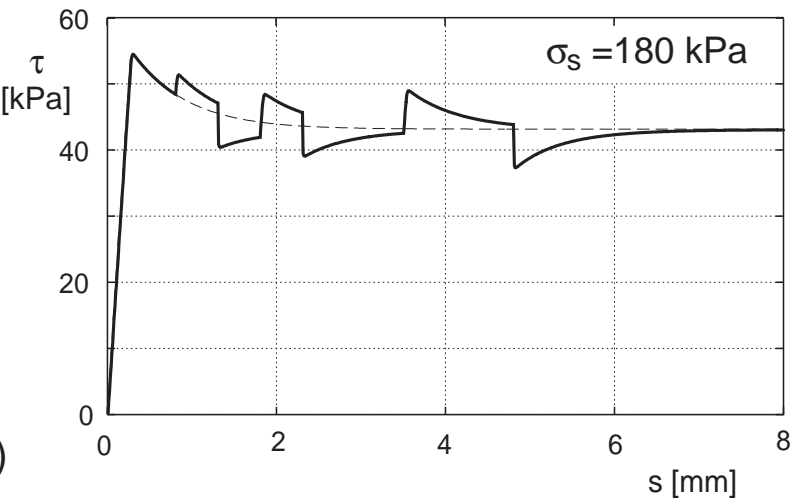

Fig. 7. Numerical back analysis of the tests of Fig. 6 .

slickenside (Fig. 9b). The void ratio determined afterwards could not be used as the layer took up an unknown amount of water from the filter slabs after unloading.

Observed evolutions of the shearing resistance with four different average pressures $\bar{\sigma}_{s}$ are shown in Fig. 10a. The section-wise stationary resistance is proportional to $\bar{\sigma}_{s}$ (Fig. 10b) with a somewhat lower $\varphi_{c s}$ of $9.3^{\circ}$ than for lower pressures. An apparent minute increase of $\varphi_{c s}$ with $\log \dot{s}$ is negligible as against the scatter. The observed changes of sample height are not represented as the inevitable minute tilting of the top plate could not be registered precisely enough.

Some similar tests were back-analyzed with finite elements (Fig. 11). The material parameters were taken over from the tests explained in the previous Sect. 3, only $\varphi_{c s}$ was adapted to $10^{\circ}$ because of the higher $\bar{\sigma}_{s}$. Displacements were assumed only in the longitudinal cross section. The layer was represented by two rows of elements (Fig. 11a), $\varphi_{c s}=10^{\circ}$ was also taken as friction angle along the filter plates. A very low isotropic pressure was assumed for the suction along the free rim. Filtration of the pore water was allowed with a permeability of $2 \times 10^{-12} \mathrm{~m} / \mathrm{s}$. The state at the onset of shearing was simplified by assuming a constant $e$ and an isotropic $p_{s}$ according to the consolidation. Tangential shear displace-

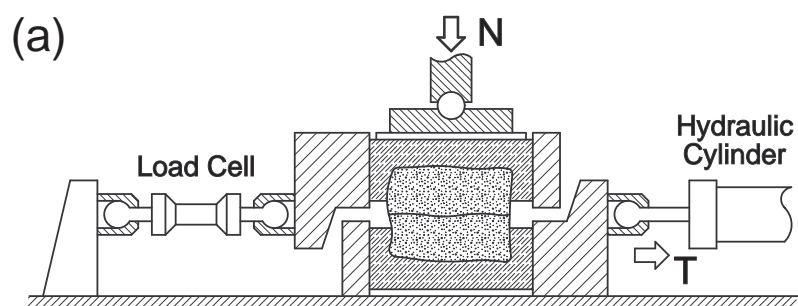

(b)

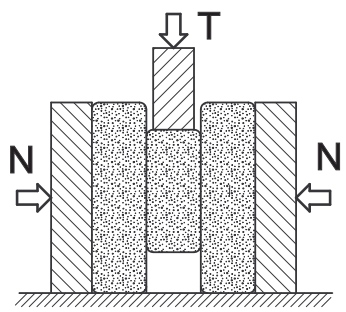

(c)

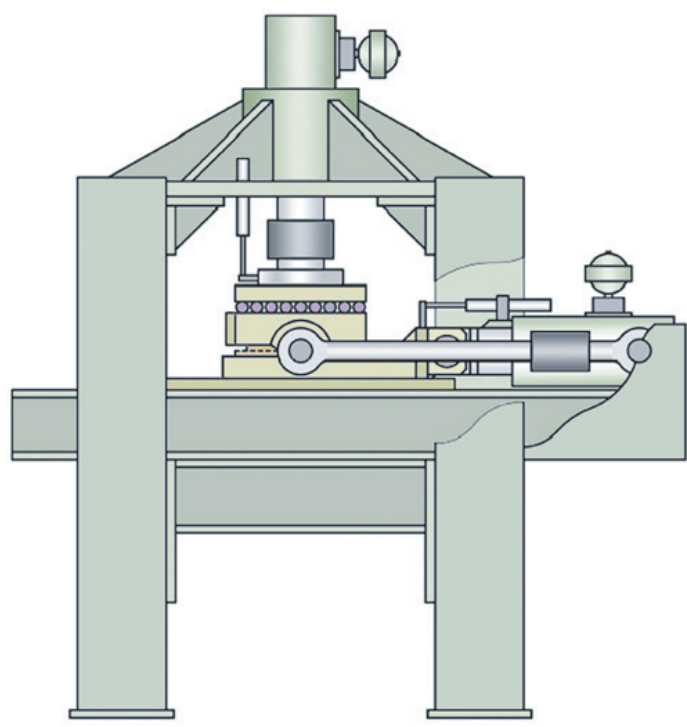

Fig. 8. Devices for shearing rock joints with shear boxes (a) and sandwich joints (b) and a self-constructed $500 \mathrm{kN}$ shear testing machine for testing rock joints (c).

ments were imposed as in the tests. A calculated distribution of $\tau$ and $\sigma_{s}$ reveals uniformity in the major part (Fig. 11b) and shows that the incertainty of the low $p_{s}$ at the rim is negligible.

Calculated evolutions of spatial average state values are shown in Fig. 12. The shearing resistance (a) is similar to the observed one, cf. Fig. 10a. Only at the onset the real sample is stiffer, persumably because of a lateral eigenstress due to frictional resistance against spreading during the compression. The agreement shows that the visco-hypoplastic model by Niemunis (2003) works also for far higher than common geotechnical pressures. The calculated average void ratios 

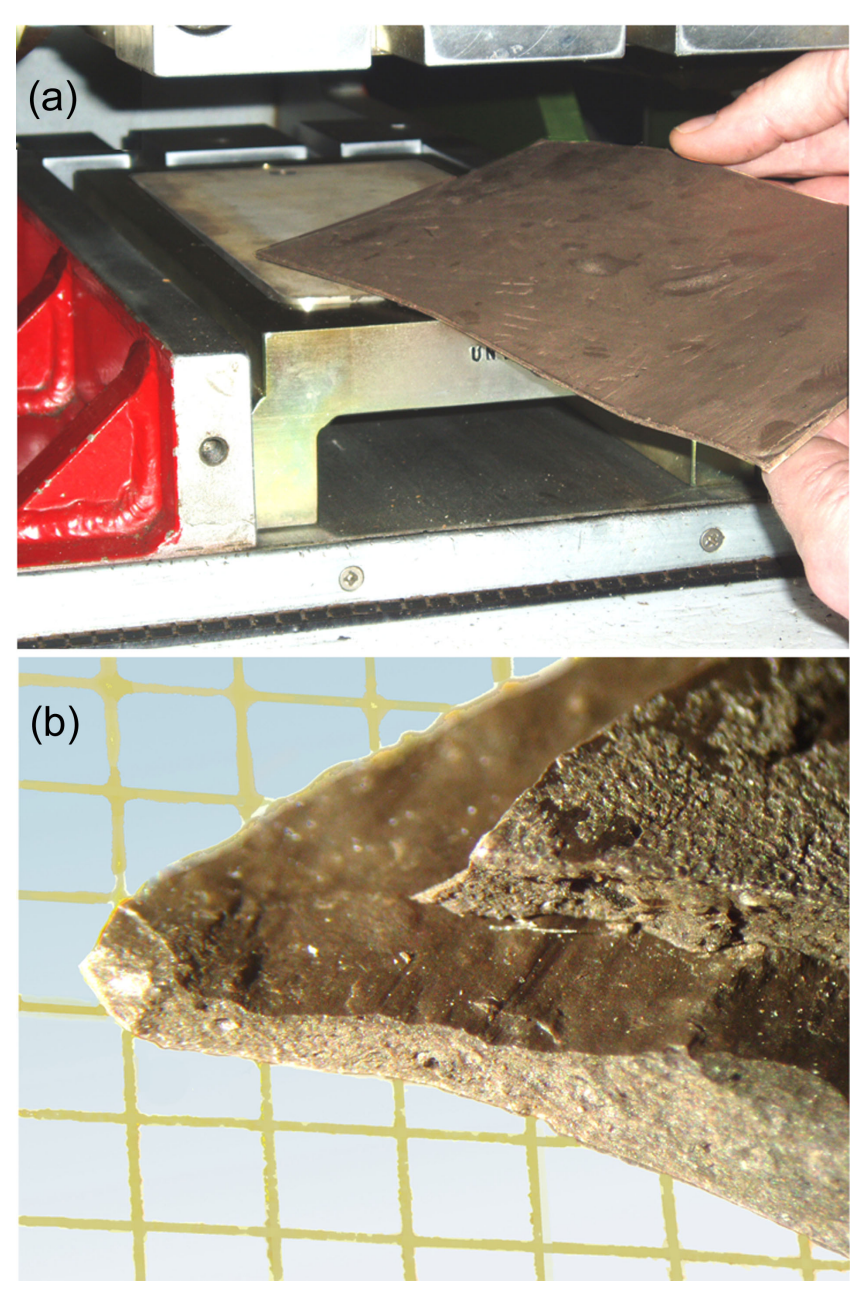

Fig. 9. Placing a thin clay layer into the shear testing machine shown in Fig. 8c (a), and magnified part of the sample with slickenside after a test (mutton rule $1 \mathrm{~mm})(\mathbf{b})$.

(Fig. 12c) are far lower than the usual geotechnical ones. Only near the rim the high initial value is not reduced.

A closer inspection reveals limitations of the constitutive model. The critical friction angle $\varphi_{c s}$ is somewhat lower for $\bar{\sigma}_{s}$ from 2 to $14 \mathrm{MPa}$ than for $\bar{\sigma}_{s}$ from 100 to $180 \mathrm{kPa}$. It appears that the argument of Bowden and Tabor (1954) for Coulomb's constant $\varphi_{c s}$, which was proposed already by Terzaghi (1925) and by Prandtl (1928) and was analyzed in detail by Persson (1998), does not hold precisely. For extremely high $\bar{\sigma}_{s}$ the clay goes over into an almost pore-free solid. Then the shearing resistance is nearly independent of $\bar{\sigma}_{s}$. As for a solid it is rate-dependent due to thermal activation, but no more for a wide $D$-range (Eq. 3), (Persson, 2000). The pore water plays also another role than for lower skeleton pressures, this will be discussed in the next section.
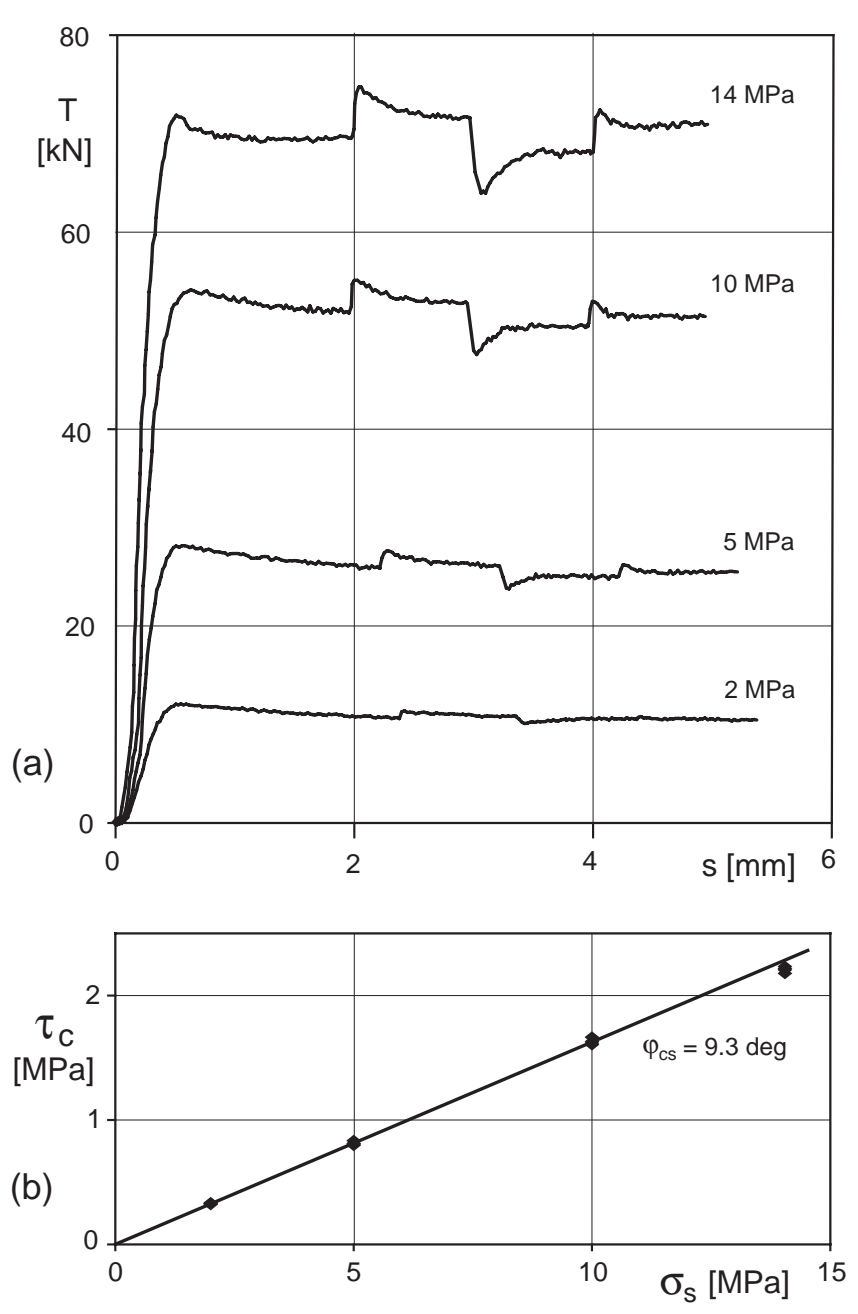

Fig. 10. Results of thin layer shear tests with high pressures: Shearing resistance vs. shear displacement (a) and stationary shearing resistance vs. normal force (b). MPa values indicate $\bar{\sigma}_{s}$.

\section{Ratcheting with high pressure}

Our shear testing machine was also equipped with a device to impose lateral motions relative to the fixed top slab, (Fig. 13). This device can produce oscillations with $2.5 \mathrm{~mm}$ peak to peak amplitude and about $0.5 \mathrm{~s}^{-1}$ frequency. Thus a kind of ratcheting was enhanced with constant normal and tangential forces.

Results of the test are shown in Fig. 14. With a constant normal force of $160 \mathrm{kN}$ (corresponding to $5 \mathrm{MPa}$ ) the shear force was increased three times in relatively short intervals and kept constant in longer ones (a). The displacement in the same direction (b) grew significantly in the shorter intervals and slowly in the longer ones. More rapid increases occured in the very short intervals with lateral oscillations (always 2 full cycles in $4 \mathrm{~s}$, dotted lines in $\mathrm{a}$ and $\mathrm{b}$ ). 
(a)
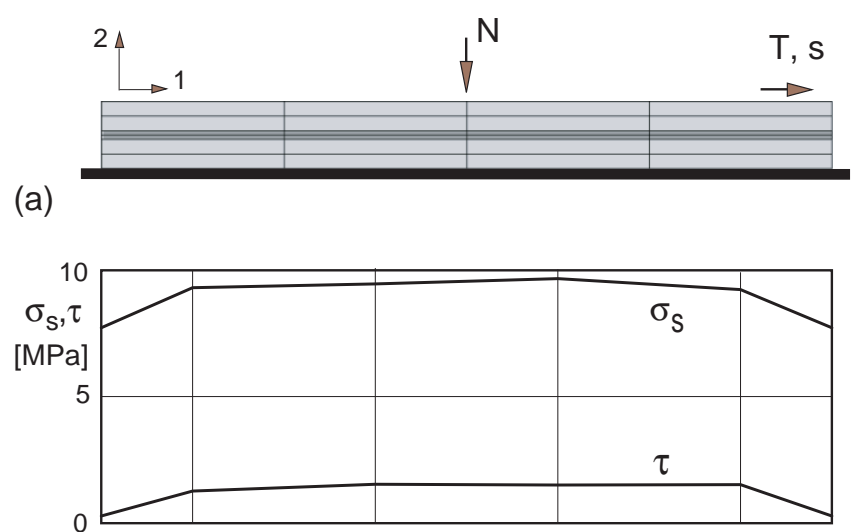

(b)

Fig. 11. Finite element model (a) with calculated stress distributions (b) by shearing.

Results of a back analysis with the visco-hypoplastic relation are also shown in Fig. 14 (dashed curves). The finite element model has the additional freedom for antiplane motions in equal parallel plane sections, Fig. 15. With the frequency of about $0.5 \mathrm{~s}^{-1}$ the deformation is rather isochoric during the oscillations so that the pore pressure increases slightly. Therefore, the imposed shear force in the simulation is somewhat lower than the one in the experiment (Fig. 14a). A kind of ratcheting is obtained for the very short intervals with lateral oscillation and for creep thereafter (b). The agreement of calculated and observed evolutions is good enough to state that Niemunis' relation is also validated for ratcheting with pressures around $5 \mathrm{MPa}$.

In a further experiment with the same short lateral oscillations of approx. $0.5 \mathrm{~s}^{-1}$ for $4 \mathrm{~s}$ the shear force was kept constant with increasing amounts in intervals from approx. 100 to $3000 \mathrm{~s}$ (Fig. 16). In the first two intervals the response to shaking is a kind of enhanced creep as in the experiment shown by Fig. 14. This could again be modelled with viscohypoplasticity. Beyond the critical shear force by Eq. (1) with $\varphi_{c s}=9.3^{\circ}$ the creep suddenly goes over into very rapid sliding. With the slight previous consolidation due to the antiplane shaking the sample could carry an $8 \%$ higher than critical shear force of approx. $26 \mathrm{MPa}$ for ca. $2500 \mathrm{~s}$. The sample dilated slowly as predicted by visco-hypoplasticity, this could not be observed precisely when collapsed in a sudden burst.

A satisfying numerical back-analysis could not be achieved for the delayed collapse. For phases of rapid shearing the low permeability prevents filtration, so with constant density of the solid particles and the gas-free pore water the skeleton deformations should be isochoric. With a lower than critical void ratio and the actual $D$ (cf. Fig. 1) this would mean a kind of hardening due to increasing suction. As long as $D$ was long enough for filtration (diffusion) the clay could
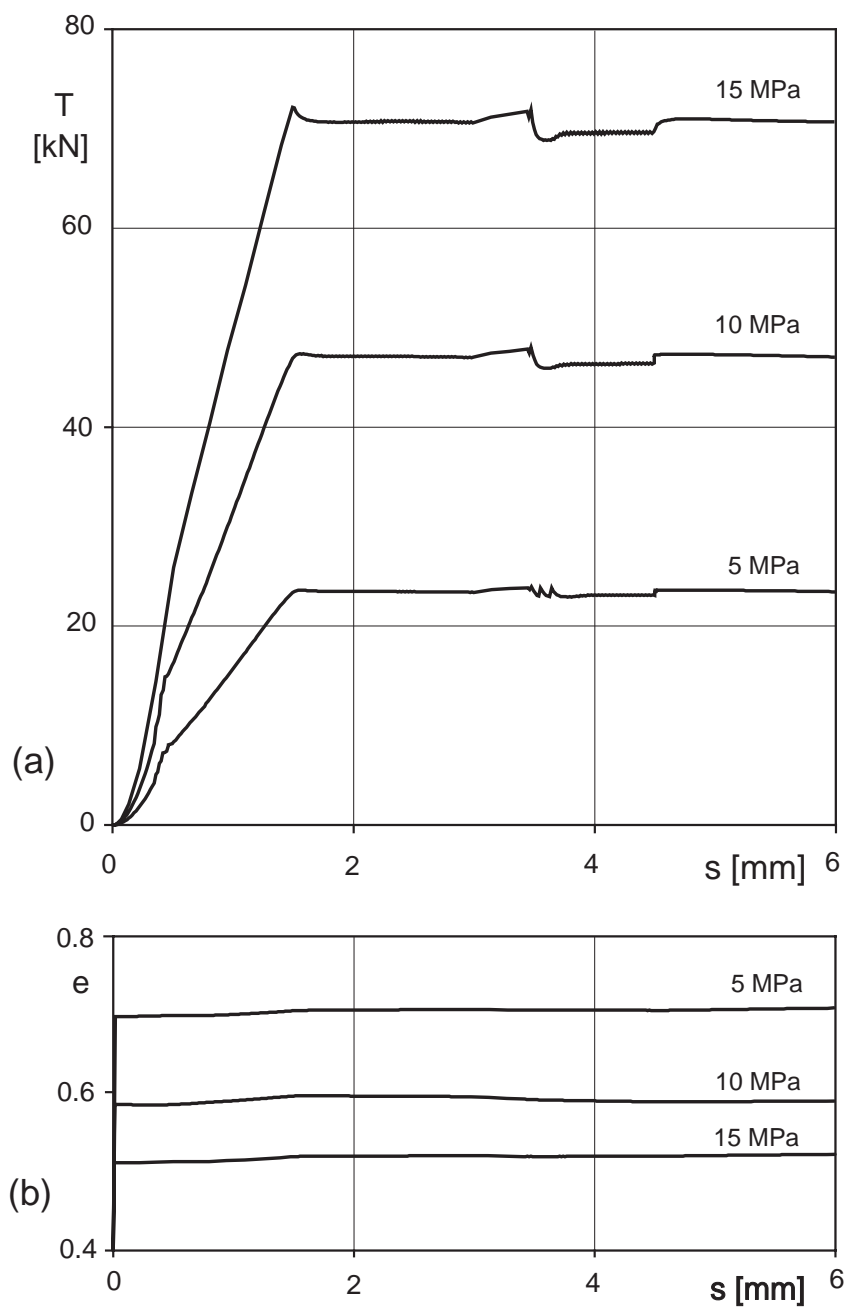

Fig. 12. Numerical back analysis of the tests of Fig. 10: Shearing resistance vs. shear displacement (a) and void ratio vs. shear displacement (b). MPa values indicate $\bar{\sigma}_{s}$.

dilate, thus its shearing rate also should accelerate alongside with a take-up of water from the filter plates for a while.

The observed rapid acceleration indicates a rapid dilation without pore water diffusion. The shearing resistance is only due to the pressure and density of the solid particle skeleton, so this must depressurize and dilate in case of an acceleration. A mechanism for the required widening of the voids could be cavitation of the pore water due to high suction. Temperley and Chambers (1946) observed cavitation of pore water for underpressures of ca. 2 to $4 \mathrm{MPa}$ in glass spheres cooled after heating. Cavitation of pore water may be presumed from the observed brittleness of the thin samples exposed after our experiments. The conditions for cavitation could at best be crudely estimated. Evolutions with cracks are rather chaotic and could scarcely be simulated with finite elements. 


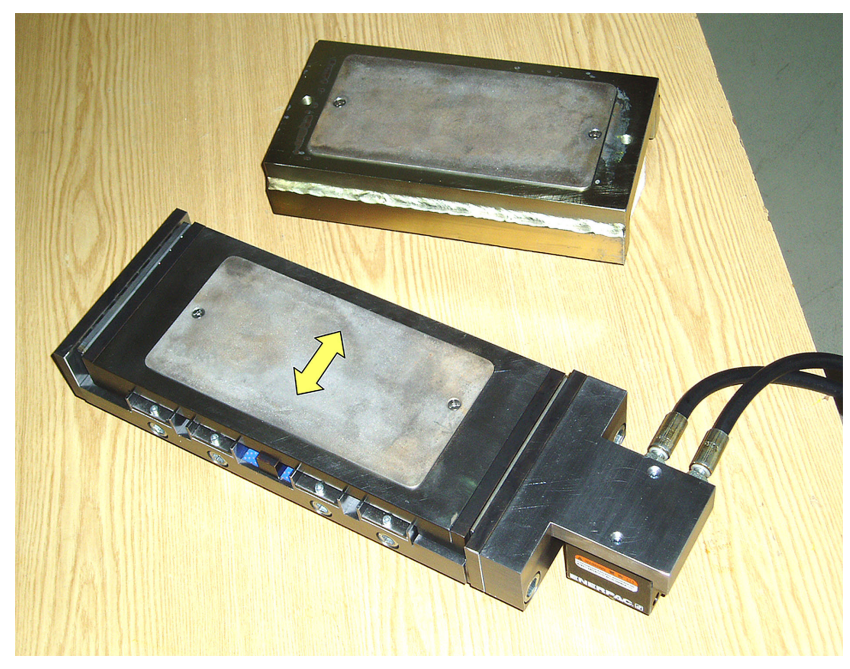

Fig. 13. Devive to produce lateral oscillation in the shear testing machine of Fig. 8c.

(a)
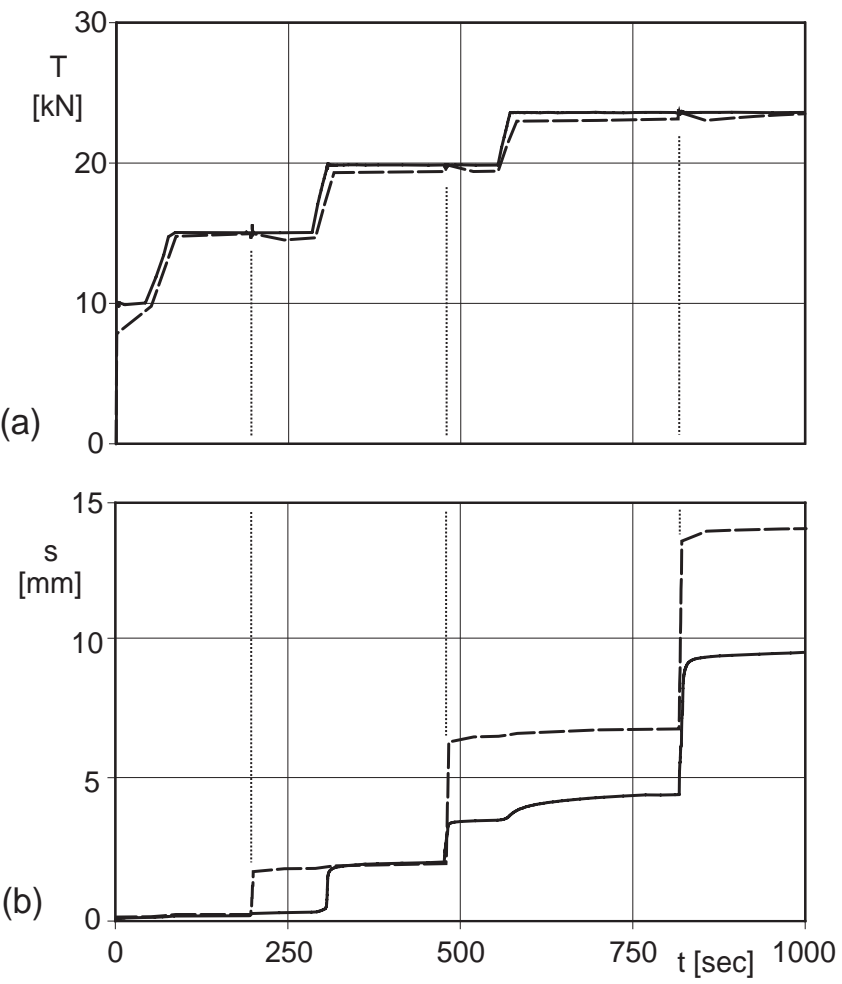

Fig. 14. Thin layer shear test with antiplane shaking: Shear force (a) and shear displacement (b) vs. time, antiplane shaking for $4 \mathrm{~s}$ at each vertical dotted line. Full lines from experiment, dashed lines show simulation with visco-hypoplastiticity. $\bar{\sigma}_{s}=5 \mathrm{MPa}$.

A second mechanism for dilation without filtration could be shear melting of less mobile pore water. Derjaguin and Churaev (1973) demonstrated that water in narrow capil-

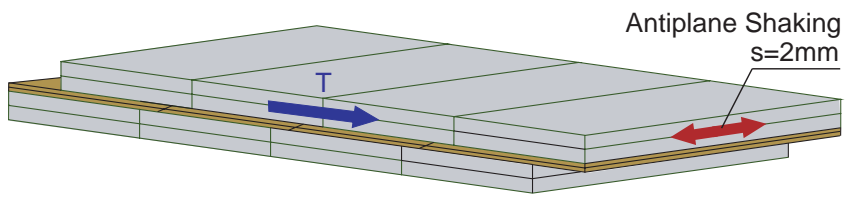

Fig. 15. Finite element model for shearing with anti-plane shaking.

laries or slits can have a somewhat higher density and a much higher viscosity than water in the bulk. The thicker so-called polywater exists at equilibrium in a narrow confinement (Gelb et al., 1999). It can be dilated by shearing (Stevens and Robbins, 1991) so that its viscosity is reduced substantially. The latter can also be deduced from the observed non-linear permeability of clays (Zou, 1996). In the geotechnical range the minute dilation of undrained saturated clay samples can hardly be observed (Külzer and Gudehus, 2005). With high pressures and low void ratios the volume fraction of polywater is higher, but could as yet not be quantified. Thus it cannot yet be decided whether the rapid dilation revealed by Fig. 16 is due to shear melting or cavitation.

\section{Conclusions and outlook}

The validity of the visco-hypoplastic relation by Niemunis (2003) could be demonstrated within and beyond the geotechnical range by means of novel thin layer shear tests with a highly plastic clay and by their back analyses. For stationary shearing the critical friction angle is slightly reduced with higher pressures, whereas the skeleton pressure for a given void ratio has the same argotropy due to thermally activated dislocations. Rate-dependence and creep with dilation or contraction are well reproduced for lower and higher pressures. The isochoric shearing enhanced by superimposed shear cycles (ratcheting) can be predicted realistically with the aid of an internal state variable named intergranular strain.

This is the base for geotechnical applications beyond the usual regime. With a specific weight minus hydrostatic uplift of approx. $20 \mathrm{kN} / \mathrm{m}^{3}$, a vertical stress of $14 \mathrm{MPa}$ corresponds to a depth of $14000 / 20=700 \mathrm{~m}$. For bigger depths Eq. (2) gets debatable, but the formula by Bauer (1996)

$e=e_{o} \exp \left[-\left(3 p_{s} / h_{s}\right)^{n}\right]$

is a capable substitute of Eq. (2). Therein the exponent $n$ ranges from approx. 0.2 to 0.5 . The solid hardness $h_{s}$ ranges from approx 0.5 to $5 \mathrm{MPa}$ for clays, and the factor $e_{o}$ from approx. 2 to 5. With Eq. (4) the limit void radios tend to zero for extremely high pressures $p_{s}$, which is physically reasonable. The critical friction angle $\varphi_{c}$ (or $\varphi_{c s}$ ) is reduced with higher $p_{s}$ and tends to zero for $p_{s} \rightarrow \infty$. Bauer's formula (Eq. 4), used in the visco-hypoplastic relation by Gudehus 
(2004) thus works also for higher pressures. Thin layer shear tests for higher normal stresses $\bar{\sigma}_{s}$ are under preparation.

The propagation of plane seismic waves through soil layers can be calculated with greater depths than in already successful applications (Cudmani et al., 2004). The stabilization of clay layers and clay-filled faults near deep mining excavations after earthquake could be proven (Bertini, 2006). The seismic interaction of ground and structures, which can be captured realistically by hypoplasticity as shown by Bühler (2006), can now be simulated for bigger dimensions. The response to repeated impacts with temporarily high pressures is also no more beyond the reach of predictions. The required material parameters can also be determined with thin layer shear tests.

Some extensions of constitutive relations and associated experimental methods are more or less under way. Gudehus (2004) extended the theory by Niemunis (2003) for a wider range of pressures and strain rates and with a pressuredependent lower bound of void ratios. For further validation experiments are needed with observation of pore pressure, void ratio and their evolution. Further experiments with shear cycles and ratcheting will serve to improve the approach with intergranular strain. Microscopic inspections can help to understand the internal state including cracks and slickensides.

The pore water will also be investigated more in depth. Triaxial tests with the same clay are under way to observe the minute dilation during deformations without drainage. The onset of cracking is investigated with rapid triaxial and shear tests. The non-linear permeability is observed in confined samples in order to get further indications of cavitation and shear thinning. A tentative constitutive relation describes the evolution of the average pore water density alongside with the one of the skeleton during deformations. This will also deepen the understanding of shear localization. State limit conditions for the opening or healing of cracks, depending on shear rate, pressure and temperature, have been formulated.

On this base some tectonic evolutions could be better understood. The evolution of normal faults could already be captured by means of hypoplasticity (Gudehus and Karcher, 2006). The sudden softening of clay in faults by combined shear melting of pore water and dilation of the skeleton could explain the cold volcanism with a breakthrough of methane. Last not least the spontaneous chaotic ratcheting as in earthquakes could be simulated on a better physical ground. Other than in approaches as by Shkoller and Minster (1997) the state variables in the visco-hypoplastic model are physically well defined. Shear experiments with deterministic chaos as the one shown by Fig. 16 could be carried out also with dynamic self organisation.

Edited by: G. Zoeller

Reviewed by: one referee
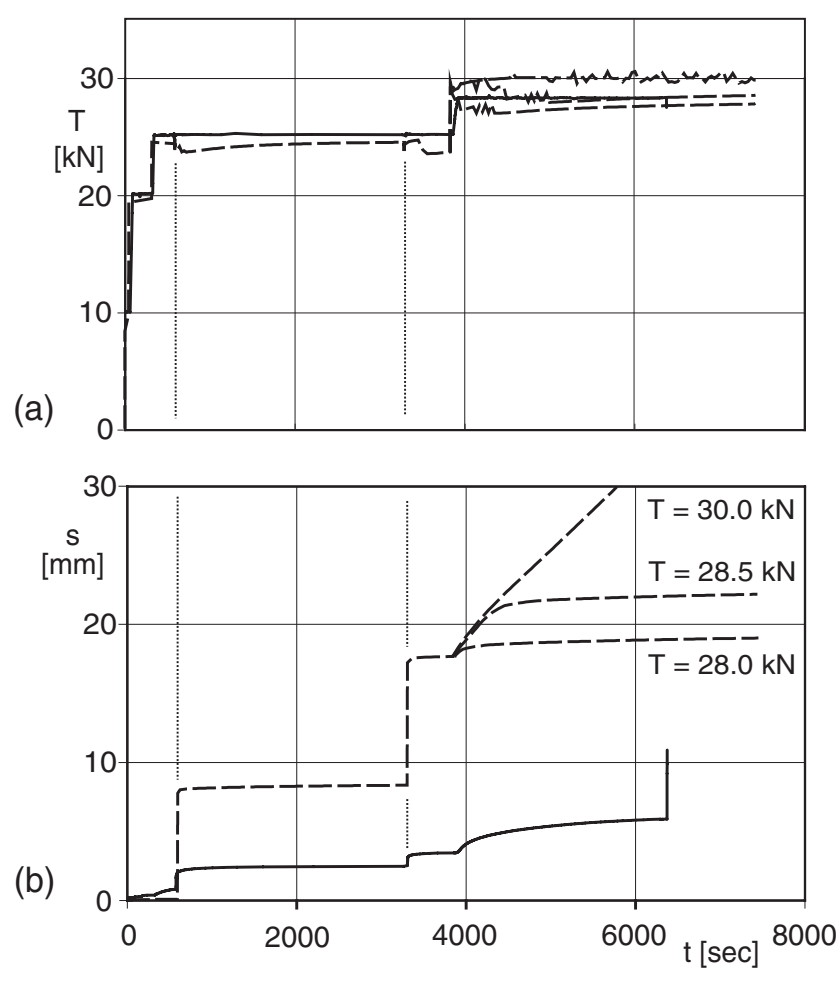

Fig. 16. Thin layer shear test with antiplane shaking and delayed collapse, antiplane shaking for $4 \mathrm{~s}$ at each vertical dotted line. Full lines from experiment, dashed lines show simulation with viscohypoplastiticity for different shear forces. $\bar{\sigma}_{s}=5 \mathrm{MPa}$

\section{References}

Bauer, E.: Calibration of a comprehensive hypoplastic model for granular materials, Soils and Foundations (Jap. Soc. of Soil Mech. and Foundation Eng.), 36(1), 13-26, 1996.

Bernaix, J.: New laboratory methods of studying the mechanical properties of Rocks, Int. J. Rock Mechanics and Mining Science, 6, 43-90, 1969.

Bertini, A. B. L.: Hypo- und viskohypoplastische Modellierung von Kriech- und Rutschbewegungen, besonders infolge Starkbeben, Veröffentlichungen des Institutes für Bodenmechanik und Felsmechanik der Universität Fridericiana in Karlsruhe, Issue 165, Karlsruhe, 2006.

Bowden, F. B. and Tabor, D.: The friction and lubrication of solids (2nd Ed.), Clarendon Press, Oxford, 1954.

Bühler, M. M.: Experimental and numerical investigation of soilfoundation-structure interaction during monotonic, alternating and dynamic loading, Veröffentlichungen des Institutes für Bodenmechanik und Felsmechanik der Universität Fridericiana in Karlsruhe, Issue 166, Karlsruhe, 2006.

Casagrande, A.: On liquefaction phenomenon, Géotechnique, 21(3), 197-202, 1971.

Cudmani, R., Osinov, V. A., Bühler, M. M., and Gudehus, G.: A model for evaluation of liquefaction susceptibility in layered soils due to earthquakes, in: 12th Pan-American Conference on SMGE, Cambridge, USA, 2, 969-976, 2004. 
Derjaguin, B. and Churaev, N. V.: Nature of 'anomalous water', Nature, 244, 430-431, 1973.

Dieterich, J. H.: Time-dependent friction in rocks, J. Geophys. Res., 77(20), 3690-3697, 1972.

Gelb, L. D., Gubbins, K. E., Radhakrishnan, R., and SliwiniskaBartkowiak, M.: Phase separation in confined systems, Reports on Progress in Physics, 62, 1573-1659, 1999.

Gudehus, G.: A visco-hypoplastic constitutive relation for soft soils, Soils and Foundations (Jap. Soc. of Soil Mech. and Foundation Eng.), 44, 11-25, 2004.

Gudehus, G. and Karcher, Ch.: Hypoplastic simulation of normal faults without and with clay smeers, Structural Geology, in print, 2006.

Külzer, M. and Gudehus, G.: Density changes of the pore water of saturated clay, in: Proc. Powders and Grains 2005, Balkema Publishers, 2, 1087-1090, 2005.

Mandl, G.: Mechanics of tectonic faulting - models and basic concepts, Elsevier Science Publishers B.V., Amsterdam, 1988.

Niemunis, A.: Extended hypoplastic models for soils, Schriftenreihe Institut für Grundbau und Bodenmechanik, RuhrUniversität Bochum, Issue 34, Bochum, 2003.

Niemunis, A. and Herle, I.: Hypoplastic model for cohesionless soils with elastic strain range, Mechanics of Cohesive-Frictional Materials, 2, 279-299, 1997.

Norton, F.: The creep of steel at high temperatures, Mc Graw Hill Book Company, Inc., New York, 1929.
Persson, B. N. J.: Sliding Friction: Theory and Applications, Springer, Heidelberg, 1998.

Persson, B. N. J.: Theory of time-dependent plastic deformation in disordeered solids, Phys. Rev. B, 61, 5949-5966, 2000.

Prandtl, L.: Ein Gedankenmodell zur kinetischen Theorie der festen Körper, Angewandte Mathematik und Mechanik, 8.2, 85-106, 1928.

Sangrey, D. A., Henkel, D. J., and Esrig, M. I.: The effective stress response of a saturated clay soil to repeated loading, Can. Geotechnical J., 6, 241-252, 1969.

Shkoller, S. and Minster, J.-B.: Reduction of Dietrich-Ruina attractors to unimodal maps, Nonlin. Processes Geophys., 4, 63-69, 1997 , http://www.nonlin-processes-geophys.net/4/63/1997/.

Stevens, M. J. and Robbins, M. O.: Shear melting of colloids: A nonequilibrium phase diagram, Phys. Rev. Lett., 66(23), 30043007, 1991.

Temperley, H. N. V. and Chambers, L. G.: The behaviour of water under hydrostatic tension (Parts I and II), Proc. Phys. Soc. London, 58, 420-443, 1946.

Terzaghi, K.: Erdbaumechanik auf Bodenphysikalischer Grundlage, Deutike, Leipzig und Wien, 1925.

Zou, Y.: A non-linear permeability relation depending on the activation energy of pore liquid, Géotechnique, 46, 769-744, 1996. 